\title{
The conquering of North America: dated phylogenetic and biogeographic inference of migratory behavior in bee hummingbirds
}

\author{
Yuyini Licona-Vera and Juan Francisco Ornelas ${ }^{*}$ (1)
}

\begin{abstract}
Background: Geographical and temporal patterns of diversification in bee hummingbirds (Mellisugini) were assessed with respect to the evolution of migration, critical for colonization of North America. We generated a dated multilocus phylogeny of the Mellisugini based on a dense sampling using Bayesian inference, maximumlikelihood and maximum parsimony methods, and reconstructed the ancestral states of distributional areas in a Bayesian framework and migratory behavior using maximum parsimony, maximum-likelihood and re-rooting methods.
\end{abstract}

Results: All phylogenetic analyses confirmed monophyly of the Mellisugini and the inclusion of Atthis, Calothorax, Doricha, Eulidia, Mellisuga, Microstilbon, Myrmia, Tilmatura, and Thaumastura. Mellisugini consists of two clades: (1) South American species (including Tilmatura dupontii), and (2) species distributed in North and Central America and the Caribbean islands. The second clade consists of four subclades: Mexican (Calothorax, Doricha) and Caribbean (Archilochus, Calliphlox, Mellisuga) sheartails, Calypte, and Selasphorus (incl. Atthis). Coalescent-based dating places the origin of the Mellisugini in the mid-to-late Miocene, with crown ages of most subclades in the early Pliocene, and subsequent species splits in the Pleistocene. Bee hummingbirds reached western North America by the end of the Miocene and the ancestral mellisuginid (bee hummingbirds) was reconstructed as sedentary, with four independent gains of migratory behavior during the evolution of the Mellisugini.

Conclusions: Early colonization of North America and subsequent evolution of migration best explained biogeographic and diversification patterns within the Mellisugini. The repeated evolution of long-distance migration by different lineages was critical for the colonization of North America, contributing to the radiation of bee hummingbirds. Comparative phylogeography is needed to test whether the repeated evolution of migration resulted from northward expansion of southern sedentary populations.

Keywords: Bee hummingbirds, Biogeography, Mellisugini, Molecular phylogeny, Migration, North America

\section{Background}

Bird migration is one of the most extraordinary behaviors found in nature. The voyage for migration involves a fascinating suite of characters including navigational systems, physiological specializations and the seasonal timing of events $[1,2]$. Our knowledge of several ecological aspects of migration has become impressive

\footnotetext{
* Correspondence: francisco.ornelas@inecol.mx

Departamento de Biología Evolutiva, Instituto de Ecología, A.C., Carretera

Antigua a Coatepec No. 351, El Haya, Xalapa, 91070 Veracruz, Mexico
}

over time $[3,4]$; however, much remains to be learned on how long-distance seasonal migration repeatedly evolved in a wide variety of bird lineages and about the selection pressures underlying the evolution of migration [5-8]. In particular, the origin and geographical directionality of long-distance seasonal migration has been widely debated in the literature (e.g., [7]), centered in two prominent ideas originated on the examination of current distributions of migratory species and their presumed sister species: the 'southern-home' and the 'northern-home' hypotheses. The 
'southern-home' hypothesis posits that the breeding migratory species from the temperate regions are returning to their tropical ancestral ranges during the winter, whereas the 'northern-home' hypothesis postulates that the ancestral temperate range of migratory species becomes harsh for survival and depart to the novel tropics during the winter, and then returning to their ancestral home for breeding $[6,9]$. In the 'southern-home' hypothesis, it is assumed that migration should evolve from sedentary ancestors to migratory descendants in response to ecological change or vice versa in the 'northern-home' hypothesis [10].

Escaping from intraspecific competition and the environmental seasonality with low food availability during the breeding season has been interpreted as being crucial for the evolution of migration [6, 11-13]. However, other factors such as increased harshness of climatic conditions and variation in resource availability during the non-breeding season, predation or parasitism would also make species to shift their breeding ranges and become migrants $[6,12]$. Likely, migrant populations originating from southern tropical regions might have shifted their ranges northwards through long-distance dispersal coupled with climatic cycles [14], assuming competition in the tropical breeding ranges or the use of seasonally abundant resources in temperate regions as the driving forces for the northward expansion and evolution of migration $[2,6,9,15]$. Several authors have envisioned scenarios for the transition from a sedentary to a migratory species over evolutionary time $[9,11,12,16]$. As a result of the differential effects of intraspecific and interspecific competition, increasing seasonality of climate or by certain patterns of climatic change during the Tertiary and Pleistocene glaciations, Cox [11] proposed that migration evolves from changing the initial sedentary condition to that of a partial migrant, having with both permanent sedentary populations and populations migrating into seasonally favorable adjacent areas. Partial migrants then evolve further through extinction of sedentary populations and expansion into derived forms with separate or disjunct seasonal ranges. In contrast, Levey and Stiles [16] developed a scenario where temporal and spatial variation of resources, especially for fruit- and nectar-feeding birds, led to altitudinal intra-tropical migration, predisposing these birds to migrate out of the tropics.

Despite the appeal of intraspecific competition and variation in resource availability as being the first step for the evolution of migration, these scenarios have several shortcomings (reviewed in [6]) including those that have shown how in a small fraction of recentlyexpanded populations migratory behavior can increase rapidly when favored by selection (e.g., $[17,18])$. Therefore, the repeated evolution of long-distance seasonal migration within bird lineages linked to the occurrence of relatively fast range expansions to take advantage of abundant resources could be the result of selective pressures occurring throughout several climatic cycles affecting resource availability in seasonally changing environments.

More recently, Somveille and collaborators [19-22] examined global spatial patterns in the diversity of migratory birds, and found strong support for the hypothesis that seasonality is the main force driving bird migration worldwide (see also [23]). Whereas the previous studies attempt to explain the ecological mechanisms driving the higher diversity of migratory species in the Northern Hemisphere [22, 23], Rolland et al. [8] used molecular phylogenies that included most extant bird species to infer that sedentary behavior is ancestral and that migratory behavior evolved independently multiple times during the evolutionary history of birds. They also found that seasonal migration increases diversification via sedentary populations arising from migratory populations (asymmetrical speciation), in which speciation of ancestral species into one sedentary and one migratory species was more frequent in migratory species than sedentary. Their results suggest that the evolution of seasonal migration in birds has facilitated diversification through the divergence of migratory subpopulations that become sedentary, and illustrate asymmetrical diversification as a mechanism by which diversification rates are decoupled from species richness.

Hummingbirds (Trochilidae) are one of the largest bird families, with ca. 338 species distributed in the Americas [24]. The most recent molecular phylogeny suggests that hummingbirds split from their sister group, swifts and treeswifts, ca. 42 million years ago (MYA) in Eurasia and that the age of the common ancestor of hummingbirds in South America is ca. 22 MYA [25]. Given the gap between these two events and the absence of relevant fossils in the Americas, McGuire et al. [25] hypothesized that hummingbirds reached North America by dispersal across Beringia. After that, hummingbirds dispersed to the South American continent and may have become extinct both in Europe and North America [25]. Hummingbirds have diversified into nine clades (Topazes, Hermits, Mangoes, Brilliants, Coquettes, Patagona, Mountain Gems, Bees, Emeralds), seven of which rapidly diversified in South America in conjunction with the Andean uplift. The common ancestor of the other two clades, Bees and Mountain Gems, recolonized North America ca. 12 MYA [25], before the formation of the Central American land bridge and closure of the Isthmus of Panama. While hummingbird diversification probably increased in conjunction with the Andean uplift according to divergence dating using substitution rate priors (rather than fossil calibrations) [25], other divergence-dating 
analyses using both fossil calibrations and substitution rate priors retrieved older divergence splits between Bees and Mountain Gems (20-25 MYA; [26]), suggesting that North American hummingbirds are not recent colonizers and may have only become extinct in Europe [26, 27].

The 'bee' hummingbirds (Mellisugini tribe; [24]) comprise an assemblage of 16 genera and 36 small species distributed throughout the Americas, from southern Canada to South America [28]. Although some species are geographically widespread (e.g., Archilochus spp.; [28]), other have very restricted distributions such as the smallest bird of the world (Mellisuga helenae) endemic to Cuba. The most extensive molecular phylogeny of hummingbirds to date [25], with at least one representative species for each genus in the Mellisugini, estimated its relatively recent origin (ca. 5 MYA), revealed a high rate of diversification (0.57 species/MYA), as compared to other hummingbird clades. This phylogeny retrieved Mellisugini as composed of two main clades: one clade included species informally named "woodstars" distributed in South America and Tilmatura dupontii with distribution in Central and North America, and the second clade contained species arranged as in two subclades: (1) Calypte, Selasphorus and Atthis species, and (2) "sheartails" (Doricha eliza and Calothorax lucifer), Archilochus (A. colubris and A. alexandri), Calliphlox evelynae and Mellisuga minima, in which phylogenetic relationships between the "sheartails" and the other species within the subclade are not supported. Besides the high rate of diversification, Mellisugini species are distinguished by the dimorphic tail morphology, which in males the rectrices are unusual in shape to produce sounds and acrobatic courtship displays during the breeding season (e.g., [29-32]).

Mellisugini is the only group of hummingbirds with long-distance seasonal migration and, therefore, an interesting study group from a biogeographic perspective. Most of the species in Canada and the USA are obligate, long-distance seasonal migrants, which vacate their entire breeding range to winter mainly in Mexico [28]. Several aspects of hummingbird long-distance seasonal migration are particularly remarkable, with journeys across the Gulf of Mexico by Archilochus colubris or those of more than $6000 \mathrm{~km}$ by Selasphorus rufus, breeding in western United States and Canada and overwintering in Mexico [33]. However, the origin and evolution of migratory behavior and the impact on hummingbird diversification has not been studied. The evolution of hummingbird migration is a complex phenomenon to address because it is thought to evolve rapidly in response to selection [9, 34-36]. Previous phylogenetic hypothesis [25] suggests that migratory behavior is not evolutionarily constrained, as both sedentary and long-distance migratory species seem to have evolved repeatedly within the Mellisugini. Understanding the evolution of migratory behavior within the Mellisugini is important, particularly because they are susceptible to rapid evolutionary change, i.e. their high rate of net diversification with species accumulation during their brief 5 MYA history [25], and because they can change their migratory behavior to escape from increased harshness of climatic conditions during the Pleistocene glacial cycles [37], and from seasonal changes in the phenology and availability of nectar floral resources by current global climate changes [38]. Unfortunately, the lack of a wider geographic sampling and the absence of some North American representative species from previous phylogenetic analyses, has not allowed having a fully resolved phylogeny of the group to understanding the evolution of long-distance seasonal migration and timing of diversification and colonization patterns.

The objectives of our study were to: (1) reconstruct the phylogenetic relationships among bee hummingbirds increasing both geographical and intraspecific sampling, (2) estimate divergence times between species and genera, and (3) reconstruct the ancestral range at each divergence event, and subsequent temporal and geographical shifts on migration in bee hummingbirds. The suite of morphological and behavioral characters coupled with the wide variety of environments where they live, including the most xeric environments tolerated within hummingbirds, have been linked to their relatively rapid radiation with highest rate of species' accumulation [25]. Thus, the Mellisugini present a useful model for exploring hidden biodiversity due to its wide distribution in both North and South American continents and recent biogeographic origin, and for understanding the potential impact of shifts between sedentary and long-distance migratory behavior on diversification of bee hummingbirds because migratory and non-migratory species, and species with partial migration (migratory and non-migratory populations) occur only in the North American continent.

\section{Methods}

\section{Sampling and laboratory methods}

The data set included 116 samples of bee hummingbirds from North America and the Caribbean Islands and 1-2 samples of bee hummingbirds from South America ( $n=16$ samples), representing all 16 genera of bee hummingbirds (32 of the 36 extant species, 89\%). Tissue samples were unavailable for four species: Chaetocercus astreans (Colombia), C. berlepschi (Ecuador), C. heliodor (Colombia, Venezuela and Ecuador), and Mellisuga helenae (Cuba). Most of these species are endemic and range-restricted; Chaetocercus berlepschi is threatened by habitat loss $[39,40]$. We include new sequence data for 60 individuals from the genera Archilochus, Atthis, Calothorax, Doricha, Calypte, Selasphorus and Tilmatura 
to supplement the data set in McGuire et al. [25] and Feo et al. [31]. Additionally, we included a single individual of each of 15 species of mountain gems and emeralds to be used for sequence alignment and as outgroups. Samples were obtained from vouchered tissue collections (see Acknowledgements) and from our collecting efforts in Mexico.

DNA was extracted from tissue or tail feathers with the DNeasy Tissue extraction kit (Qiagen, Valencia, CA, USA) using the standard protocol. We amplified and sequenced six gene regions, two mitochondrial protein coding genes-1041 base pairs (bp) of nicotinamide dehydrogenase subunit 2 (ND2) and 807 bp of nicotinamide dehydrogenase subunit 4 (ND4), and four nuclear loci-1085 bp of fibrinogen beta chain intron (FBG I7), $551 \mathrm{bp}$ of adenylate kinase 1 intron 5 (AK1 I5), $577 \mathrm{bp}$ of ornithine decarboxylase 1 introns 6 and 7 intervening exon (ODC1), and 635 bp of Z-linked muscle, skeletal, receptor tyrosine kinase intron 3 (MUSK I3) using specific primers (Additional file 1). Protocols for PCR reactions and for sequencing the PCR products are described elsewhere [41]. The products were read on a 310 automated DNA sequencer (Applied Biosystems) at the INECOL's sequencing facility. Finally, assembled sequences were edited and checked for quality, pre-aligned using MAFFT v7 (http://mafft.cbrc.jp/alignment/server/), and then manually aligned using PhyDE [42]. Newly generated sequences have been submitted to GenBank (Accession nos. ND2: KX855335- KX855393; ND4: KX855394- KX855450; AK1 I5: KX855451- KX855509; MUSK I3: KX855568- KX855624; ODC1: KX855510KX855567; FBG I7: KX855625- KX855637; Additional file 2). The alignments supporting the results of this article are available in the Dryad Digital Repository (http:// dx.doi.org/10.5061/dryad.68fn0) as Licona-Vera and Ornelas [43].

\section{Phylogenetic reconstruction}

The phylogeny was reconstructed using Bayesian inference (BI), maximum-likelihood (ML) and maximum parsimony (MP). We performed BI comparative phylogenetic analyses using MrBAYES v3.2.2 [44] and the CIPRES Science Gateway [45] on the following data sets: (1) only mitochondrial genes ('unpartitioned mtDNA'), (2) only mitochondrial genes as two partitions ("partitioned mtDNA'), (3) only nuclear genes ('unpartitioned nuDNA'), (4) only nuclear genes as four partitions ('partitioned nuDNA'), (5) combined loci data set with a single model ('concatenated'), (6) each DNA region as one partition ('mtDNA + nuDNA'), and (7) with a set partition-specific DNA evolution models of each gene ('6-partitions'). We used jMODELTEST v2.1.7 [46] to select an appropriate model of nucleotide substitution for each locus and the concatenated data set. GTR + I + G (ND2), TrN + I + G
(ND4), K80 + G (AK1 I5), HKY (MUSK I3), HKY (ODC1), $\mathrm{HKY}+\mathrm{G}$ (FBG I7), GTR + I + G (mtDNA data set), GTR + G (nuDNA data set), and $\operatorname{TrN}+\mathrm{I}+\mathrm{G}$ (concatenated) were selected as the best fitting models and incorporated as prior information in the Bayesian analyses. For each data set, two parallel Markov chain Monte Carlo (MCMC) analyses were executed simultaneously for 30 million generations, sampling every 10,000 generations. Output parameters were visualized using TRACER v1.6 (http://tree.bio.ed.ac.uk/software/tracer/). A $25 \%$ burn-in was used, and a majority rule consensus tree was calculated and visualized in FIGTREE v1.4.3 (http:// tree.bio.ed.ac.uk/software/figtree/). We computed Bayes factors with the harmonic means [47] to determine whether applying partition-specific models for the combined data sets significantly improved the explanation of the data.

The ML analysis for the concatenated data set was run using RAxML v8.2.9 [48] with a GTRGAMMA model for each partition. Node support for the ML tree was estimated with 1000 bootstrap replicates.

The MP analysis was run for the concatenated data set in NONA v2.0 [49] using WINCLADA [50], with nucleotide characters treated as equally weighted and unordered. We ran 1000 iterations, holding 10 trees per iteration with $10 \%$ of the nodes constrained, and all the parameters set to default. Branch support was assessed using bootstrap resampling, 1000 bootstrap-resampled pseudo-replicate matrices were each analyzed using 100 random addition sequences (multi*100). Ten trees were retained during TBR swapping after each search initiation (hold/10).

\section{Divergence time estimation}

A Bayesian relaxed-clock analysis was performed in BEAST v2.4.4 $[51,52]$ to assess species divergence times using the six genes. We constrained Trochilidae and the hummingbird clades used as outgroups (emeralds and mountain gems) as monophyletic based on McGuire et al. [25]. Divergence times were estimated using an uncorrelated lognormal relaxed clock model across all genes, with the trees linked and the substitution models for each partition unlinked [53]. We calibrated our divergence-dating analyses using a Yule speciation model and three calibration strategies for divergence time estimation: (1) incorporating a separate normally distributed substitution rate calibration priors for ND2, ND4, AK1, $F G B$, and $O D C$ using the mean substitution rates proposed by Lerner et al. [54] to model the tree prior, allowing the substitution rate prior for MUSK I3 to be calculated by BEAST because no substitution rate was available; (2) using as secondary calibration the age of the split between mountain gems and bee hummingbirds (normal, mean 12.0 MYA, SD \pm 1, range of 13.9-10.3 
MYA) according to McGuire et al. [25] to calibrate the root of the tree; and (3) using both strategies, secondary calibration + substitution rates. This strategy was also used for divergence time estimation using a reduced data set, which includes one individual for each of the species to contrast results of divergence time estimation from single vs. multiple-individuals data sets.

Two independent chains of MCMC were run with 50 million generations, sampling every 5000 generations. Results were visualized in TRACER v1.6 (http:// tree.bio.ed.ac.uk/software/tracer/) to confirm appropriate burn-in, adequate effective samples sizes (ESS > 200) of the posterior distribution for all parameters, and to assess convergence among runs by comparing likelihoods of parameters. The three independent runs were combined with LOGCOMBINER v2.4.4 [51, 52] and the resulting maximum clade credibility tree and $95 \%$ highest posterior (HPD) distributions of each estimated node annotated using TREEANNOTATOR v2.4.4 [51, 52] and visualized in FIGTREE v1.4.3 (http://tree.bio.ed.ac.uk/).

\section{Ancestral areas of bee hummingbirds}

We reconstructed ancestral geographic ranges using Bayesian methods with BBM (Bayesian Binary MCMC) analyses implemented in RASP v3.2.1 [55]. This method determines the probability of each ancestral geographical region for each node averaged over the collection of trees derived from a Bayesian MCMC analysis [56, 57]. To reconstruct the ancestral areas, we loaded 6000 trees from the Bayesian Inference analyses using MrBAYES. The breeding distributions of each sample was obtained from del Hoyo et al. [28] and crossed with the status and distribution information compiled by the Cornell Laboratory of Ornithology as input (www.allaboutbirds.org/ guide). We coded each individual in the data set as occurring in one or more of the following areas: $\mathrm{A}=$ western North America, B = eastern North America, C = southeastern Mexico and Central America, $\mathrm{D}=$ West Indies, and $\mathrm{E}=$ South America (Additional file 3). These regions were based on a modified map of the ecoregions (http://maps.tnc.org/gis_data.html) proposed by Blair and Sánchez-Ramírez [58]. The posterior probabilities for nodes in the phylogeny with $>0.90$ were estimated to incorporate information from most nodes of the tree but minimizing phylogenetic 'noise' from poorly supported relationships. The maximum number of areas in ancestral ranges was constrained to three, Amazilia rutila assigned as outgroup using the 'custom' option, and the ancestral areas for nodes visualized on the condensed tree. Analyses were run for 50,000 iterations, sampling every 100 generations, the first $25 \%$ of which were discarded as burn-in, with the JC + gamma model of state transitions used as input.

\section{Evolution of migratory behavior}

Ancestral state reconstruction was used to map migratory behavior onto the resulting molecular phylogeny. The evolution of migratory behavior was reconstructed using maximum parsimony (MP) and maximumlikelihood (ML) methods. We traced the evolution of migratory behavior over the molecular phylogeny using two topologies: one with all samples and the other with one sample per species. The first topology corresponds to the best estimate of Mellisugini phylogenetic relationships using the 6-partitions data set (see Results), a Bayesian 50\% majority rule consensus tree of 132 samples of bee hummingbirds. We used the 18,000 postburnin trees from the BEAST analysis to account for the phylogenetic uncertainty in the ancestral state reconstruction. The second topology was a Bayesian 50\% majority rule consensus tree using one sample per species (see Results). This tree was obtained from a BEAST analysis using the same parameters and the 6-partitions strategy described on methods section of phylogenetic reconstruction.

For ancestral state reconstruction we used three different coding schemes mainly based on information in del Hoyo et al. [28] and Malpica and Ornelas ([37]; Additional files 3 and 4). In coding Scheme 1 species that migrate seasonally between different latitudinal geographical breeding and wintering ranges were coded as migrants (i.e., obligate, long-distance migration; [59]) and non-migratory species were coded as sedentary. For this coding scheme, we also considered as migratory those species with partial migration, in which some individuals or populations are fully migratory across their range and other individuals or populations are sedentary (Selasphorus platycercus and Calothorax lucifer; [60]). The migratory state does not include tropical hummingbird species that may undertake altitudinal or shortdistance migration at the fringes of their northern ranges in the northern temperate region (e.g., Amazilia violiceps, Eugenes fulgens, Heliomaster constantii; [59]). In coding Schemes 2 and 3, species with partial migration were coded as sedentary or polymorphic, respectively, to test the robustness of our conclusions to potential ambiguities in character state coding [60]. Coding species with a simple binary codification (sedentary or migrant) and pruning trees to species probably mask or confuse the ancestral character reconstruction of species susceptible to rapid evolutionary change of migratory behavior [34-36]. Thus, we conducted ancestral state reconstruction using the data set with multiple individuals for a given species to compare results with those obtained for species-level analyses (single-individual data set). Also, insights might be gained from sampling several individuals if these provide the signal at the phylogenetic level of when the shifts from migratory to sedentary (or vice versa) occurred 
between populations in species with both sedentary and migratory populations. Here, single individuals of $C$. lucifer and S. platycercus with migratory and sedentary populations were classified as either migrant or sedentary based on data on Malpica and Ornelas [37] and because samples of single individuals were collected during the breeding season from known allopatric migratory or sedentary populations. Species names, English names and distributional range for the Mellisugini species used in this study are provided in Additional file 5.

MP and ML based ancestral state reconstruction were conducted in Mesquite v3.11 [61] using each of the coding schemes of migratory behavior described above. To account for topological uncertainty we used the 'trace character over trees' option, which summarizes the ancestral state reconstruction over a series of trees. All reconstructions were integrated over the last 18,000 post burn-in of the Bayesian analysis and the ancestral states were summarized using the 'Count trees with uniquely best states' option on the maximum credibility tree using Mesquite. A reconstruction is regarded as equivocal when there are two or more equally parsimonious states inferred at a particular node. For the parsimony ancestral character reconstructions character-state changes were set as unordered, with other parameters as default. In the ML approach, the character state for each ancestral node was reconstructed using the Markov kstate 1 parameter model (Mk1), which specifies an equal probability of any state change and considers the rate of change the only parameters. We conducted ancestral state reconstruction with more than one method because each of the two methods described above suffers from certain advantages and limitations [62-66].

Ancestral states of migratory behavior in the Mellisugini were also reconstructed using the re-rooting method of Yang et al. [67] as implemented in PHYTOOLS v0.5 [68] in $\mathrm{R}$ v3.3.0 [69]. This method re-roots the phylogeny at every node and calculates the phylogenetically independent contrast for the root node, taking advantage of the fact that this value is the maximum likelihood estimate for that node [70, 71]. We used the Mk1 model for reconstruction of the character state for each ancestral node, assuming equal rate of evolution. Since the likelihood approach is not applicable for polymorphic characters this reconstruction was performed using only the parsimony approach.

\section{Results}

\section{Phylogeny}

Bayesian analyses using the entire gene data set (nuDNA + mtDNA) resulted in a well-supported phylogeny of the Mellisugini tribe and close relatives (Fig. 1). The summary of MP and ML bootstrap values and the Bayesian posterior probabilities are presented on the branches of the BI 50\% majority-rule consensus tree (Fig. 1). Results of other
Bayesian analyses using partition or unpartitioned nuDNA or mtDNA data sets are given in Additional file 6. Given the stronger support between clades in the analyses of the nuDNA + mtDNA data set and Bayes Factors, we considered the MrBayes results of concatenated mtDNA + nuDNA genes (with 6-partitions strategy) to be our best estimate of phylogenetic relationships in the Mellisugini. We rely on this tree in our ancestral state reconstructions and discussion of the evolution of migration and of biogeography. Changes to previous phylogenetic topologies of the Mellisugini (e.g. [25]) are indicated in Additional file 7.

\section{Divergence dating and ancestral areas of bee hummingbirds}

The topology of the BEAST time-tree using the third calibration strategy (secondary calibration + substitution rates (Fig. 2) was concordant with those derived from other reconstruction methods (Fig. 1, Additional file 6). The BEAST analyses indicated the most recent common ancestor (MRCA) for the Mellisugini originated approximately 9.93 MYA (95\% HPD 11.94-7.92 MYA) in mainland North America $~ 6$ million years before the final closure of the Isthmus of Panama (Fig. 2). The ancestor originated in either western North America or southern Mexico and Central America, with relatively high support for nodes A (separating bee hummingbirds and mountain gems) and B (separating South and North American bee hummingbirds) yielded by the ancestral area reconstruction (AC, 97\% and 79\%, respectively; Fig. 2). By the end of the Miocene, the bee hummingbirds first reached western North America (node C; A, 60\%). Accordingly, subsequent major nodes (nodes D, E, F, K, J) were reconstructed as nearly $100 \%$ western North America (A). Although it is uncertain where the ancestor of bee hummingbirds was distributed in the region, the analysis suggests that western North America was colonized during the early diversification of the group with dispersals into other regions of the Northern Hemisphere. The BEAST analyses also showed a mid-to-late Miocene split separating South American woodstars from the other bee hummingbirds (node B; Fig. 2), divergence of the Mexican sheartails from other North American bee hummingbirds in the late Miocene (node $\mathrm{C}$ ), and that the diversification of the South American woodstars (node L), Caribbean sheartails (node $\mathrm{H}$ ) and the split between the CalypteSelasphorus subclades (node E) occurred in the early Pliocene (Fig. 2). Details of ages for other nodes of interest are shown in Table 1.

\section{Evolution of migratory behavior}

The results of ancestral state reconstruction of longdistance migratory behavior on the Bayesian 50\% majority-rule consensus tree of a reduced 32 bee 


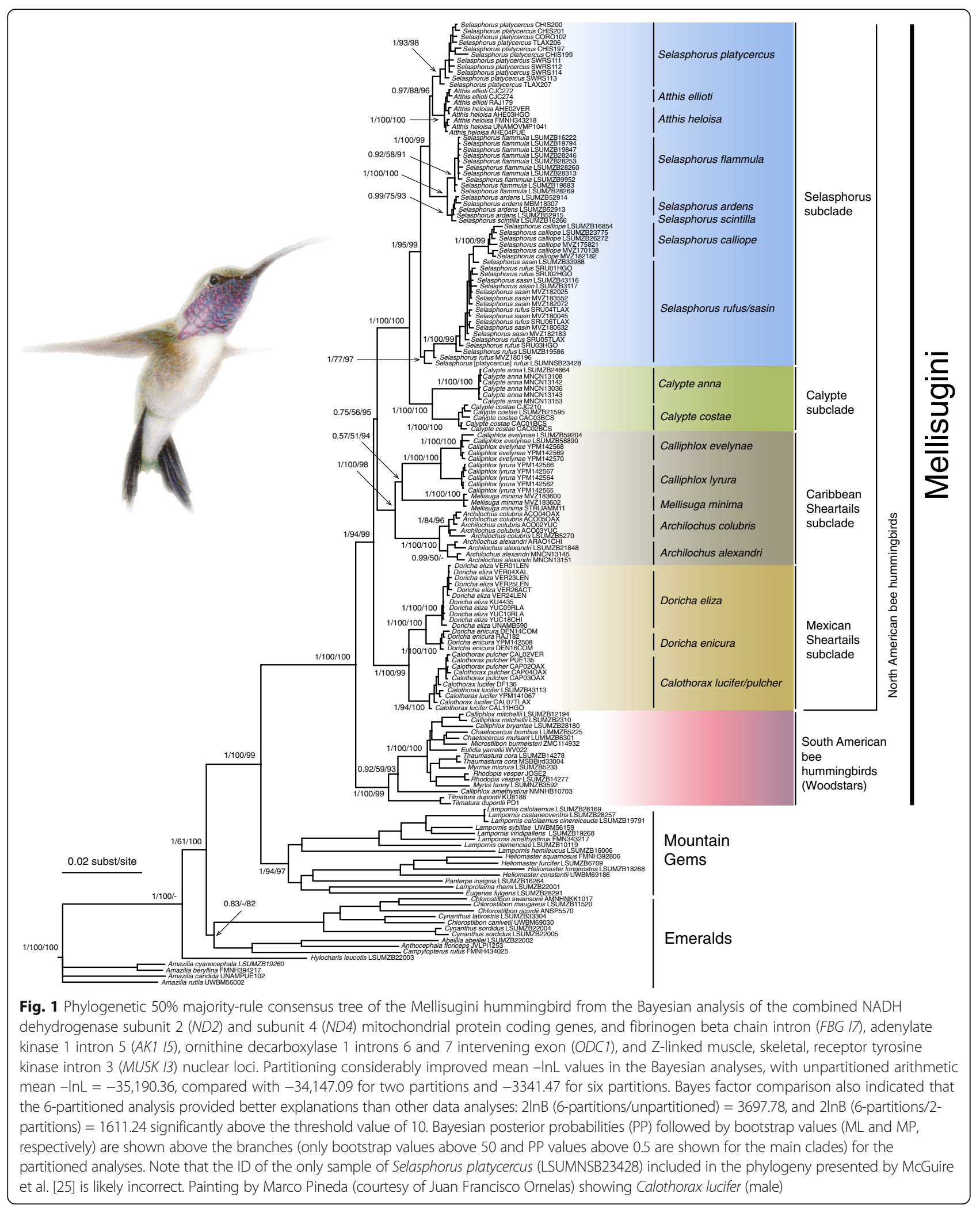




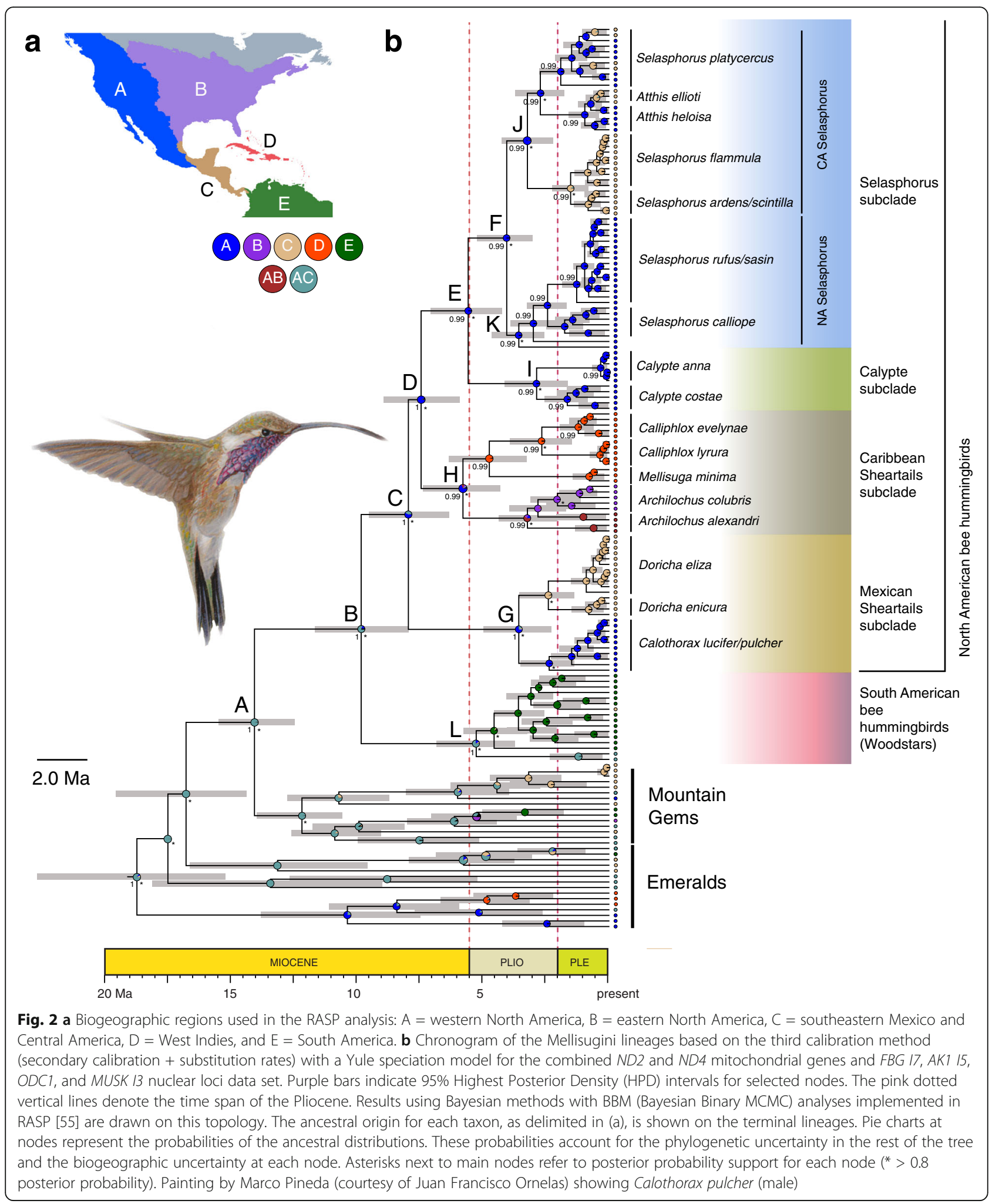

hummingbird species data set using only one individual per species and the 6-partitions strategy (Additional file 8) are shown in Fig. 3. The MP and ML reconstructions of migratory behavior provided similar results with high certainty in the bee hummingbirds, in which the phylogenetic position of migratory species indicates multiple independent origin of long-distance migratory behavior (Fig. 3a-c). ML, MP, and the re-rooting method of Yang 


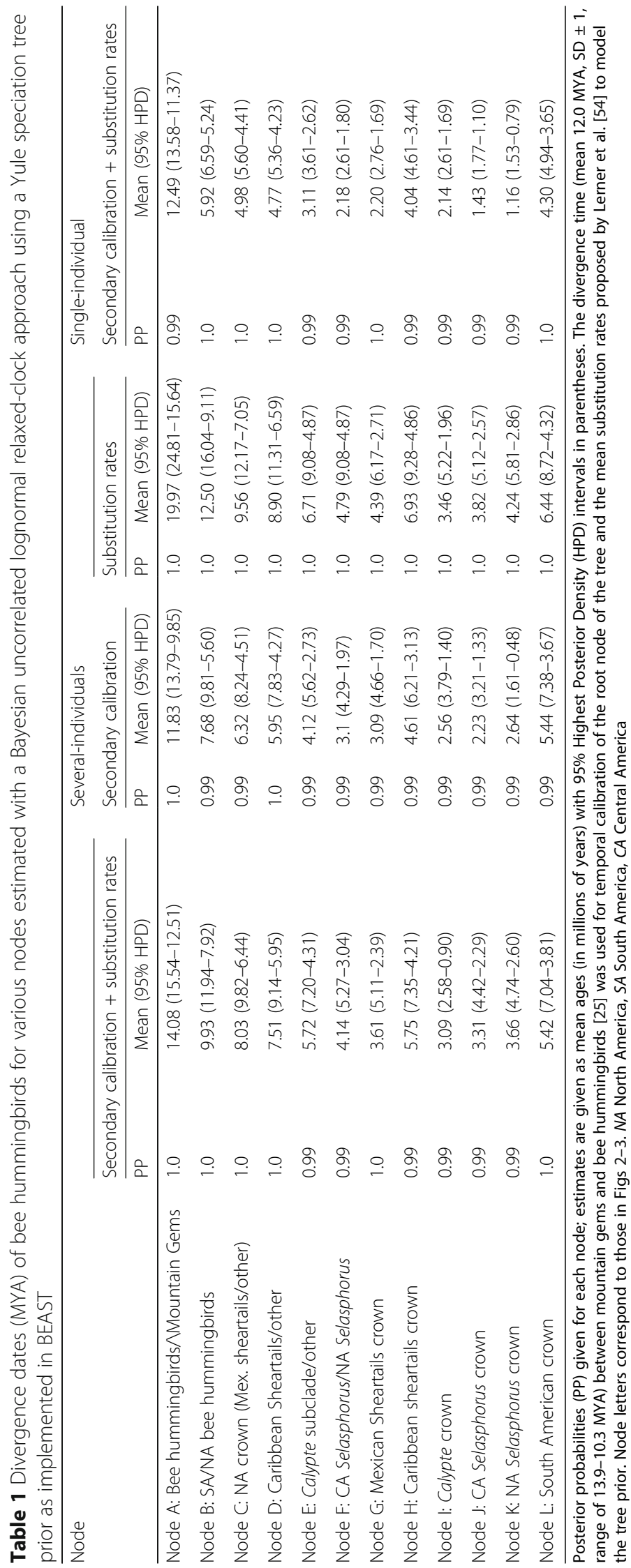




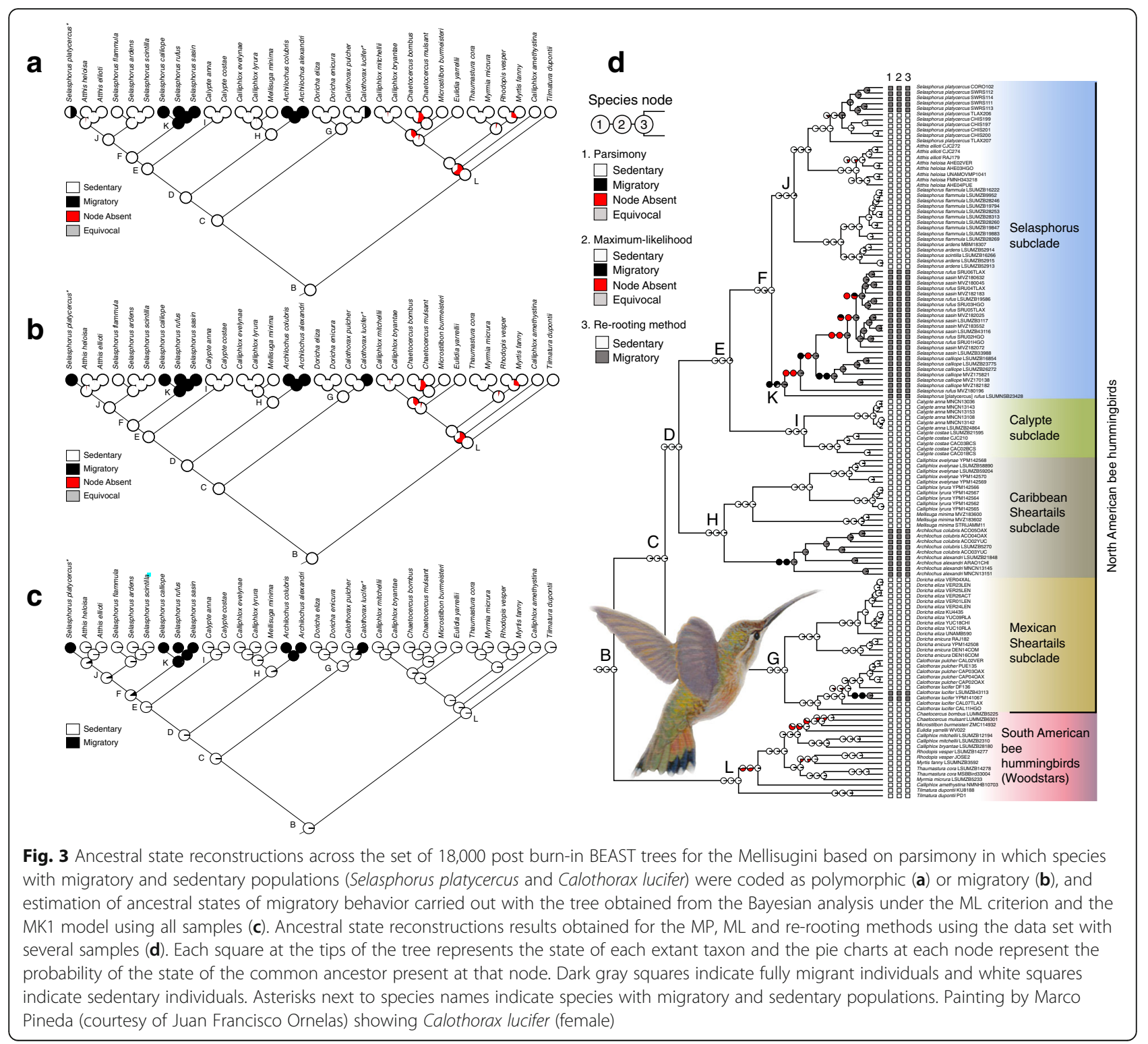

et al. [67] ancestral-state reconstructions supported a sedentary ancestral mellisuginid (bee hummingbird) regardless of the coding scheme used for migratory behavior (Fig. $3 \mathrm{a}-\mathrm{c}$ ). Because the results using the various coding schemes were largely the same, we only present the results based on one of the coding schemes for each of the ancestral state reconstructions: parsimony and species with partial migration (C. lucifer and S. platycercus) coded as polymorphic (Fig. 3a), and maximum likelihood and rerooting with $C$. lucifer and S. platycercus coded as migratory (Fig. 3b-c). Basal nodes of all North American subclades (incl. Monophyly of Caribbean sheartails) were reconstructed with strong support for the sedentary state with MP, ML and re-rooting methods (Fig. $3 \mathrm{a}-\mathrm{c}$ ), and migratory behavior was gained four times during the evolution of the Mellisugini: once in the Mexican sheartails subclade (Calothorax lucifer) and the Caribbean sheartails subclade (Archilochus species), and twice in the Selasphorus subclade (Selasphorus rufus, S. sasin and $S$. calliope group and S. platycercus). Similar results were obtained for the MP, ML and re-rooting ancestral state reconstructions using the data set with several samples (Fig. 3d), except that migratory behavior was been lost at least once in S. platycercus (see also [37]).

\section{Discussion}

Phylogeny of bee hummingbirds

Our phylogenetic analyses recovered a monophyletic South American clade sister to other bee hummingbirds in Central America, the Caribbean islands and North America. Despite this, the backbone of our tree topology is not entirely consistent with that for previous studies 
with fewer taxa and individual samples ([25, 72]; see Additional file 7). According to our analyses, Mexican sheartails split very soon after the split between South American and North American bee hummingbirds, and sister to remaining subclades. The Selasphorus subclade is composed of two groups according to our results, the North American Selasphorus (S. calliope, S. sasin, S. rufus) and the Central American Selasphorus arranged by geography, S. flammula, S. scintilla and S. ardens from Costa Rica and Panama and S. platycercus, Atthis heloisa and A. ellioti mainly from Mexico and Guatemala.

Our DNA sequence data set (including 162 samples and 2-6 loci for each sample) contains $8.8 \%$ missing data, and this incompleteness is unlikely to have negatively impacted the accuracy of phylogenetic reconstruction because the number of characters in the analysis is large [73, 74]. Perhaps adding more taxa and more samples per taxon improved the accuracy of our phylogenetic reconstruction, in which monophyly of the Caribbean sheartails (Archilochus, Mellisuga, Calliphlox) is strongly supported. Lastly, our dense individual sampling within S. platycercus indicated that this species is nested within the group of Central American Selasphorus and Atthis species, the Selasphorus subclade, and did leverage our phylogenetic and ancestral state reconstructions from ID errors in single-individual species representation of previous phylogenetic reconstructions.

\section{Divergence dating and ancestral areas of bee hummingbirds}

According to our results, the crown age of the Mellisugini, ca. 9.93 MYA using the 'several-individuals' data set and the 'secondary calibration + substitution rates' calibration strategy, is older than those estimated by McGuire et al. [25] and Abrahamczyk and Renner [72], 5.3 and 7.22-6.71 MYA, respectively. When using the 'single-individuals' data set and the 'secondary calibration + substitution rates' calibration strategy, the crown age of the Mellisugini is similar, ca. 6.59-5.24 MYA (Table 1). These obvious differences across studies are likely due to the different calibration strategies and taxon sampling employed. McGuire et al. [25] included 27 species and 61 samples of bee hummingbirds and Abrahamczyk and Renner [72] 25 species and 26 samples, whereas our study included 32 species and 132 samples. A discrepancy in age estimates is observed in the comparison of the posterior mean age estimates between the 'single-individual' species samples and the 'several-individuals' species samples (taxon sampling variation) for the 6-partitions data sets (Table 1). In this case, we know that all sampling and data conditions are identical between the two analyses except for the density of taxon sampling within species. The age estimates for the Mellisugini (nodes B-L) differ on average by about 2 MYA, with the all sampling consistently yielding older ages leading to very different biogeographic conclusions. Although the difference is greater for the deeper nodes in the tree, the impact becomes minor as one moves to the tips of the tree (Fig. 2, Table 1). Our results indicated that different sampling strategies have yielded different estimates and potential errors in molecular dating likely due to sampling bias for recent evolutionary radiations. In discussing age estimates in the subsequent discussion, we refer primarily to the posterior mean point estimated obtained with the 'several-individuals' species samples for the 6-partitions data set with more precision in divergence time estimation of shallow nodes.

The early divergences within the Mellisugini are estimated to have occurred after the mid-Miocene climatic optimum (nodes B, C and D of Fig. 2; [75]), but the majority of divergence events occurred much later, from the Pliocene to the mid-late Pleistocene (Fig. 2). Based on these results, we propose that the formation of the mountain systems in Mexico and Central America from mid-Miocene to the Pliocene was critical in providing favorable habitats and climatic conditions for the divergence of bee hummingbirds in the region. The bee hummingbirds dispersed to North America in the midMiocene, and then its history was probably marked by a period of expansion to xeric environments and segregation into xeric and moist temperate forests directly associated with a global decrease in temperature and humidity during the Late Miocene [76] and desert formation in North America [77]. Divergences of the Mexican sheartails and the Calypte and Archilochus species from their ancestors (Fig. 2) dated at 8.03, 5.72 and 5.76 MYA, respectively, coincides with the Miocene peak in speciation rates in some plants characteristic of xeric environments in Mexico, including Agave [78] and cacti [79], through a region of the country similar to that through which Calothorax is currently distributed and feed upon. The radiation of the Mellisugini in Central America, Caribbean islands and North America must have been relatively rapid. During the Late Miocene, the lineage would already be possibly occupying the main mountain ranges in Central America, and occurring in Mexico, in both montane and dry environments. The divergences of Calothorax, Archilochus, and the NA Selasphorus from their sedentary ancestors are dated at $3.09,5.75,4.14$ MYA, respectively, suggesting that these divergences occurred in the Pliocene. These divergences also coincide with the second peak in speciation rates in Agave sensu lato dated at 3-2.5 MYA influenced by nectar feeding bats [78], and the transition from beepollination to hummingbird-pollination in Mexico in the Opuntia-Nopalea cacti clade dated at 5.73 MYA (95\% HPD 8.7-3.42 MYA; [80]). In contrast, divergence of migratory S. platycercus from its sedentary ancestor is dated at 1.54 MYA (95\% HPD 2.27-0.93 MYA), 
suggesting that the evolution of migration in S. platycercus occurred in the Pleistocene as shown by ancestral state reconstruction (Fig. 3).

The Late Miocene ages of hummingbird-dependent plant clades in North America (9-5 MYA; [72] coincide with the timings of divergence events of bee hummingbirds during the Pliocene and mid-late Pleistocene (Table 1). Our interpretation is also supported by the age of the oldest hummingbird-adapted group in North America, Lonicera (Caprifoliaceae), with a stem age of 9.2 MYA and a crown age of 7.0 MYA [81], the age of hummingbird-pollinated Psittacanthus mistletoes in Mexico with a stem age of 9.68 MYA and a crown age of 7.43 MYA [82, 83], and by the Pleistocene origin of Penstemon in the Rocky Mountains with subsequent migration and radiation to the Cascade-Sierra Nevada cordillera and then into southwestern North America and throughout eastern North America [84]. Interestingly, range expansions of bee hummingbirds in North America during the Pliocene seem to correspond to Pliocene divergences within the hummingbird-pollinated Psittacanthus mistletoes apparently linked to habitat shifts $[82,83]$. For instance, the ages of the Calothorax sheartails, with a stem age of 3.6 MYA (95\% HPD 5.11-2.39 MYA) and a crown age of 2.4 MYA (95\% HPD 3.611.41 MYA), coincide with the timing of divergence events of the Psittacanthus mistletoes they currently pollinate ( $P$. auriculatus distributed in the xeric areas of Oaxaca and $P$. calyculatus distributed in pine-oak forests along the Trans-Mexican Volcanic Belt; [85-87]), with a stem age of 3.1 MYA and a crown age of 1.8 MYA [82, 83]. The ages of Calypte costae, with a stem age of 3.1 MYA (95\% HPD 4.49-1.78 MYA) and a crown age of 1.7 MYA (95\% HPD 2.58-0.91 MYA), coincide with the timing of divergence events of the Psittacanthus mistletoes they currently pollinate in the Sonoran Desert, $P$. sonorae, with a stem age of 4.8 MYA and a crown age of 0.3 MYA [82, 83].

Like the hummingbirds and their coevolved plants in North America, the earliest divergence within the Caribbean sheartails (5.7 MYA; Table 1) indicates that they were also contemporaneous with lineages of hummingbird-adapted flowers [72, 88]. Overall, the results of our divergence-dating analysis seem to indicate that the Pliocene range expansions of bee hummingbirds are connected with the biogeography of their host plants and provide interesting insights on how range expansions into North America via habitat changes facilitated the evolution of migration in this group.

\section{Evolution of migratory behavior}

Our study is the first to provide phylogenetic evidence for the repeated evolution of long-distance migratory behavior in the radiation of the Mellisugini, with the crown ancestors of the main clades and North American subclades reconstructed as sedentary. Our results suggest that long-distance seasonal migration arose independently four times in the Mellisugini: once in the Mexican sheartails subclade (Calothorax lucifer) and the Caribbean sheartails subclade (Archilochus species), and twice in the Selasphorus subclade (Selasphorus rufus, S. sasin and $S$. calliope group and $S$. platycercus). Our study also showed that migratory lineages are generally more closely related to non-migratory lineages than to other migratory lineages, and that long-distance seasonal migration arose at different times. For instance, the split between migratory Archilochus species and sedentary species endemic to the Caribbean islands (Mellisuga and Calliphlox species) occurred at 5.7 MYA, whereas genetic differentiation between migratory $C$. lucifer and $S$. platycercus and their sedentary ancestors seem to have started during the late Pleistocene.

Our ancestral area reconstruction appears to explain the migration patterns of earliest Archilochus species, earliest A. colubris breeding in eastern NA (USA and Canada) and migrant to mainly eastern Mexico, Central America and some Caribbean islands, and A. alexandri breeding in western NA (USA and Canada) and migrant to western Mexico. A phylogeographic approach accompanied with paleodistributional modeling would be needed to test whether the differences in migratory patterns between $\mathrm{Ar}$ chilochus sister species were influenced by Pleistocene climate change and their range shifts occurred earlier. Using ecological niche modeling and phylogeographic data, Malpica and Ornelas [37] showed first that S. platycercus is a niche tracker and then that the climate conditions associated with modern obligate migrants in the USA were not present during the LIG, which provides indirect evidence for recent migratory behavior in S. platycercus on the temporal scale of glacial cycles. Their study also revealed that the evolution of migration within S. platycercus produced no significant genetic structure using nuclear microsatellites (nSSRs), migratory and sedentary groups of populations form an admixed population. The fact that they detected no significant genetic differentiation between migratory populations of $S$. platycercus and sedentary populations of the species in central Mexico (platycercus subspecies) is surprising because these hummingbirds inhabit different breeding areas of the USA and Mexico, and no evidence of sympatry at overwintering sites in Mexico has been noted. However, phylogeographic analyses and population genetic methods revealed that both migratory populations in the USA and sedentary populations in Mexico of the platycercus subspecies form one admixed population, and that sedentary populations from southern Mexico and Guatemala (guatemalae subspecies) diverged earlier (0.75 MYA) and undertook independent evolutionary trajectories [37]. 
Several studies have explicitly outlined a similar framework for addressing the evolution of bird migration between North and Central America, in particular for species with migratory populations in Canada and USA and sedentary populations in Mexico and Central America [10, 89]. For example, Milá et al. [90] examined the evolution of migration in the chipping sparrow (Spizella passerina) with sedentary populations in Mexico and the southern USA and migratory populations in the northern USA and Canada, and found evidence that migration was driven by northern range expansion from sedentary populations following glacial episodes.

Our study provides phylogenetic evidence for a sedentary origin for the Mellisugini, but certainly is not the first to deal with this question in birds of the Northern Hemisphere (e.g., [60, 89-98]). Studies that have reconstructed the ancestral state of migration in a phylogenetic context have found either equivocal results $[93,99,100]$ or results in favor of a migratory $[10,60,101]$ or a sedentary ancestor $[89,92,98,102-104]$. According to a well-supported molecular phylogeny of Catharus thrushes sensu lato (incl. Hylocichla mustelina), long-distance seasonal migration is reconstructed as the ancestral condition at most basal nodes when putting character changes as close to the root of the tree as possible (ACCTRAN resolving option), and north of Mexico is reconstructed as the ancestral area with the origin of the clade at 8 MYA, diversification of Catharus from Hylocichla occurring at 6.9 MYA, and further lineage divergence within Catharus starting in the early Pliocene at 4.7 MYA [10]. Within Catharus, migratory behavior was lost after the first speciation event in the genus and was geographically and temporally correlated with Central American distributions and the final closure of the Central American Seaway. Subsequently, migratory behavior was re-gained twice in Catharus and was geographically and temporally correlated with a re-colonization of North America in the late Pleistocene [10]. Counter to our results for the Mellisugini, the ancestral wood-warbler (Parulidae) was reconstructed as migratory using the well-supported molecular phylogeny of Lovette et al. [97], with losses of migration as prevalent as gains throughout the evolutionary history of Parulidae [60]. These results suggest that extant sedentary tropical radiations in the Parulidae represent losses of long-distance seasonal migration and colonization of the tropics from temperate regions [60]. However, many derived non-migratory clades descended from non-migratory ancestors, supporting the notion that the ancestor of the Parulidae was a non-migrant [98]. Using a phylogenetic model of the joint evolution of breeding and non-breeding, wintering ranges to infer the biogeographic history in the emberizoid passerine birds, Winger et al. [101] found that seasonal migration between breeding ranges in North America and winter ranges in the Neotropics evolved primarily via shifts of winter ranges toward the tropics from ancestral ranges in North America.

In the Mellisugini, it seems that migration evolved out of the tropics through the northern extension of ancestral tropical or subtropical breeding ranges into temperate regions ('southern home-theory'; [6, 9]). According to results of the Rolland et al.'s [8] study that included most extant bird species, we infer that sedentary behavior is ancestral and migratory behavior evolved several times during the evolutionary history of the Mellisugini. Testing increased diversification rates in the Mellisugini with the evolution of migration is hampered by the lack of statistical power (see [8] for further discussion). Nonetheless, the divergence of a migratory species into two migratory daughter species tend to be less frequent that the divergence of a sedentary species into two sedentary daughter species, consistent with the findings of Rolland et al. [8] and predictions of Helbig [5] and Claramunt et al. [105] that genetic differentiation is reduced in migratory species with high dispersal capacity. The results of Rolland et al.'s [8] study suggest that the mobility of migratory species promotes the colonization of new areas and, if adapted to the new habitat, populations can become sedentary and diverge from the founding migratory species.

Several factors would have influenced the way bee hummingbirds colonized the northern portion of North America in the mid-Pliocene. Following the first dispersal of ancestral Archilochus hummingbirds from the Caribbean islands to the northeast and northwest of North America, either along the coastal slope or across the Gulf of Mexico, it is possible that range changes in the Pleistocene caused multiple populations to lose migration and stay restricted to the Caribbean Islands with subsequent speciation. Successful dispersal of North American Selasphorus hummingbirds occurred from Central America and southern Mexico to the northwest of the continent. The evolution of migratory populations from ancestral sedentary populations in southern Mexico of $S$. platycercus occurred later, likely due to Pleistocene climate changes (see also [90]). These scenarios are consistent with the idea that geographic isolation during the Late Pleistocene account for intraspecific and sister-species-level divergence largely based on habitat shifts influenced by climate change (e.g., [102, 106-108]), particularly shifts subsequent to the LGM produced distinct migratory pathways and further genetic differentiation [93, 109]. Therefore, it seems that divergence of a migratory species into two migratory daughter species is linked to a seemly rare event of changing migratory trajectories widely documented in some songbirds (e.g., [93, 109-116]). Further study using a comparative phylogeographic approach accompanied 
with ecological niche modeling and more or faster molecular markers (e.g., SNPs, SSRs) should provide finer resolution to the history of migration in the Mellisugini, particularly for contrasts between shallow lineages with sedentary and migratory species (e.g., Calothorax lucifer/ C. pulcher). For testing the effects of cyclical glacial changes on producing seasonally unstable habitats, and driving northward expansion and the evolution of seasonal migration and contraction into southern sedentary populations, and increased sampling of South American woodstars, further study will be needed to test whether the evolution of long-distance seasonal migration in North American bee hummingbirds has facilitated diversification in the Mellisugini through the divergence of migratory subpopulations that become sedentary $[8,60]$.

We cannot eliminate the possibility that long-distance migratory behavior evolved relatively early in the evolution of the Mellisugini. If this was the case, a migratory ancestor lost migration multiple times. Under this hypothesis colonization of North America and the Caribbean Islands would be more likely, despite that the phylogenetic evidence of that migratory ancestor is now lost, as temperate niches remained relatively open with ephemeral resources with subsequent losses of migratory at later times environments became less seasonal. If this model were statistically supported, its results would suggest that long-distance migratory behavior evolved once in the base of the Mellisugini tree, with several subsequent losses towards the end of the Pliocene. In coding SA bee hummingbirds and mountain-gems as migratory assuming that a migratory ancestor lost migration multiple times, ancestral character state reconstruction yielded equivocal results for the node of the Mellisugini and further ancestral nodes within the tribe were reconstructed as sedentary. When forcing only SA bee hummingbirds to be migratory, both the node of the Mellisugini and further ancestral nodes for main clades within the tribe were reconstructed as sedentary (Results not shown).

Cox's [11] model predicts that migratory species will be derived from sedentary species within the seasonal subtropics, and that migratory behavior is a derived character state. We believe that the Mellisugini lineage fits this model in many ways, particularly because most migrant species are closely related to the sedentary species found in the seasonal highlands of Mexico and Central America. An important result of our study is that long-distance migratory species do not form a monophyletic group. The relationships between migrant and resident species within the Mexican sheartails, Caribbean sheartails, and Selasphorus subclades are more complex than we expected. Also, the repeated gains of migration occurred during the Late Pliocene and this suggests that potential responses, i.e. the temporal evolution of migratory behavior, can be linked to historical, climatic and ecological events on a phylogeny [7, 10]. However, we cannot ignore the possibility that long-distance migratory behavior in the Mellisugini was the ancestral state with several drop-offs of migration. Given the high degree of lability of the trait [34-36] and assuming that the phylogenetic signal of long-distance migratory behavior in the Mellisugini is an artifact of phylogenetic inertia in biogeographic range (including latitude and temperature seasonality), these questions seem unanswerable, making long-distance seasonal migration non tractable over substantial evolutionary time until comparative genomic data sets for migratory/sedentary closely related species pairs and for migratory and non-migratory populations of species with partial migration become available.

\section{Conclusions}

Pliocene's mountain building in Mexico and Pleistocene climate changes were the primary feature that structured diversity in the Mellisugini. These results are consistent with Cox's [12] idea that the Mexican Plateau and arid southwestern United States have acted as staging areas for the evolution of hummingbird migration. Range expansions of early lineages of the Mellisugini seem to be connected with the biogeography of their host plants and provide interesting insights on how range expansions into North America via habitat changes facilitated the evolution of migration in this group. Recently evolved lineages in all subclades of the Mellisugini appear to have undergone long-distance seasonal migration, albeit in different directions. This history of repeated evolution of migration within the Mellisugini allowed for divergence across common biogeographic regions spanned by North American bee hummingbirds. It is likely that, without repeated evolution of migration in different directions, diversification of the Mellisugini would have decelerated towards the present [25]. Thus, molecular patterns of diversification within the Mellisugini reflect a dynamic history of divergence, the main lineages during the Pliocene linked to the formation of the mountain systems in Mexico and Central America and further divergence by the evolution of seasonal migration during the Pleistocene.

\section{Additional files}

Additional file 1: Primers employed in this study. (DOC 39 kb)

Additional file 2: Species names, voucher information, locality, and GenBank accession numbers for specimens sequenced in this study. (DOC $102 \mathrm{~kb}$ )

Additional file 3: Species names, distributional codes and migratory status for ancestral state reconstruction analyses of the Mellisugini species used in this study. $A=$ western North America, $B=$ eastern North America, C = eastern Mexico and Central America, D = West Indies, $\mathrm{E}=$ South America; $\mathrm{M}=$ migratory, $\mathrm{S}=$ sedentary (binary character codification). (DOC $169 \mathrm{~kb}$ ) 
Additional file 4: Migratory status of the Mellisugini species for ancestral state reconstruction analysis used in this study. $\mathrm{M}=$ migratory, $\mathrm{S}=$ sedentary. (DOC $57 \mathrm{~kb}$ )

Additional file 5: Species names, English names and distributional range for the Mellisugini species used in this study. (DOC $75 \mathrm{~kb}$ )

Additional file 6: Bayesian 50\% majority rule consensus trees of 132 representatives of bee hummingbirds (32 of the 36 extant species, $89 \%$ ), 15 of mountain gems and 15 of emeralds. The trees are based on data sets of (a) only mitochondrial genes ('unpartitioned mtDNA data set'), (b) only mitochondrial genes as two partitions ("partitioned mtDNA data set"), (c) only nuclear genes ('unpartitioned nuDNA data set"), and (d) only nuclear genes as four partitions ("partitioned nuDNA data set"). Posterior probabilities (PP) > 0.5 are shown. (PDF $930 \mathrm{~kb}$ )

Additional file 7: Comparison of backbone tree topologies of the Mellisugini. (a) McGuire et al. [25], (b) Abrahamczyk \& Renner [72], and (c) Bayesian 50\% majority rule consensus tree of 32 bee hummingbird species of this study in Additional file 7. Asterisks denote nodes with 1.0 posterior probability (PP) support. Numbers at nodes reflect posterior probabilities less than 1.0. Support values for nodes of phylogeny in (b) are not provided in Abrahamczyk \& Renner [72]. (PDF 425 kb)

Additional file 8: Bayesian 50\% majority rule consensus tree of 32 bee hummingbird species and representatives of mountain gems and emeralds used as outgroups. The tree is based on a combined data set of all available fragments of ND2, ND4, AK1 15, MUSK 13, ODC1 and FBG 17 and partition-specific DNA evolution models of each gene (' 6 -partitions data set'). Posterior probabilities (PP) $>0.5$ are shown. (PDF $404 \mathrm{~kb}$ )

\section{Acknowledgements}

We thank Cristina Bárcenas, Antonio Acini Vásquez, Andrés Ortíz-Rodríquez, Clementina González, Flor Rodríguez-Gómez, Eduardo Ruiz-Sánchez, María José Pérez-Crespo and Andreia Malpica for field and lab assistance; and Cristina González-Rubio (CIBNOR), Borja Milá (MNCN-C SIC) and Rosa Alicia Jiménez (MC: Escuela de Biología, USAC) for providing tissue samples essential to this work. The samples collected in Mexico were conducted with the permission of the Secretaría de Medio Ambiente y Recursos Naturales, Instituto de Ecología, Dirección General de Vida Silvestre (permit numbers: INE: SEMARNAP, D00-02/3269, INE SGPA/DGVS/02038/07, 01568/08, 02517/ 09, 07701/11, 13528/14, 02577/15, 06448/16). Borja Milá provided useful comments on previous versions of the manuscript. This work constitutes partial fulfillment of Y.L.V's doctorate in Biodiversity and Systematics at INECOL.

\section{Funding}

This project was funded by the Departamento de Biología Evolutiva, Instituto de Ecología, A.C. (INECOL) awarded to J.F.O. (20030/10563). Y.L.V. was supported by a doctoral scholarship (262561) from CONACyT. The publication costs were financed by the Dirección General of the INECOL (20029/60813)

\section{Availability of data and materials}

Sequence reads can be accessed through GenBank under the Accession Numbers KX855335-KX855393 (ND2), KX855394-KX855450 (ND4), KX855451KX855509 (AK1 15), KX855568-KX855624 (MUSK I3), KX855510-KX855567 (OCD1), KX855625-KX855637 (FBG 17). The new sequence (FASTA) data supporting the results of this article are available in the Dryad Digital Repository (http://dx.doi.org/10.5061/dryad.68fn0) as Licona-Vera and Ornelas [43]

\section{Authors' contribution}

The authors of this paper have a general interest in the evolutionary history of hummingbirds. For this paper, YLV was involved in collecting most samples and obtaining the molecular data, and together with JFO in performing the phylogenetic and dating analyses, writing the manuscript and interpreting the molecular and phylogenetic data. Both authors read and approved the final manuscript.

\section{Competing interests}

The authors declare that they have no competing interests.

\section{Consent for publication}

No aspect of this study required written informed consent to participate.

Ethics approval and consent to participate

No aspect of this study required ethics approval.

\section{Publisher's Note}

Springer Nature remains neutral with regard to jurisdictional claims in published maps and institutional affiliations.

Received: 28 January 2017 Accepted: 24 May 2017

Published online: 05 June 2017

\section{References}

1. Berthold P. Control for bird migration. London: Chapman and Hall; 1996.

2. Berthold P. Bird migration. 2nd ed. Oxford: Oxford University Press; 2001.

3. Faaborg J, Holmes RT, Anders AD, Bildstein KL, Dugger KM, Gauthreaux SA $\mathrm{Jr}$, et al. Recent advances in understanding migration systems of new world land birds. Ecol Appl. 2010;80(1):3-48.

4. Supp SR, La Sorte FA, Cormier TA, Lim MCW, Powers DR, Wethington SM, et al. Citizen-science data provides new insight into annual and seasonal variation in migration patterns. Ecosphere. 2015;6(1):15.

5. Helbig AJ. Evolution of bird migration: a phylogenetic and biogeographic perspective. In: Avian migration (eds P Berthold, E Gwinner, E Sonnenschein). Berlin, Germany: Springer; 2003. p. 3-20.

6. Salewski $\vee$, Bruderer B. The evolution of bird migration-a synthesis. Naturwissenschaften. 2007:94(4):268-79.

7. Zink RM. The evolution of avian migration. Biol J Linn Soc. 2011;104(2):237-50.

8. Rolland J, Jiguet F, Jønsson KA, Condamine FL, Morlon H. Settling down of seasonal migrants promotes bird diversification. Proc R Soc B. 2014; 281(1784):20140473

9. Rappole $\mathrm{JH}$. The ecology of migrant birds: a Neotropical perspective. Washington, D.C.: Smithsonian Institution Press; 1995.

10. Voelker G, Bowie RCK, Klicka J. Gene trees, species trees and earth history combine to shed light on the evolution of migration in a model of avian system. Mol Ecol. 2013:22(12):333-3344.

11. Cox $\mathrm{G}$. The role of competition in the evolution of migration. Evolution. 1968:22(1):180-92

12. Cox G. The evolution of avian migration systems between temperate and tropical regions of the new world. Am Nat. 1985:126(4):451-74.

13. Lack D. Bird migration and natural selection. Oikos. 1968;19(1):1-9.

14. Safriel UN. The evolution of Palearctic migration-the case for southern ancestry. Isr J Zool. 1995:41(3):417-31.

15. Alerstam T, Hedenström A, Åkesson S. Long-distance migration: evolution and determinants. Oikos. 2003:103(2):247-60.

16. Levey DJ, Stiles FG. Evolutionary precursors of long-distance migration: resource availability and movement patterns in the Neotropical landbirds. Am Nat. 1992;140(3):447-76.

17. Terrill SB, Berthold P. Ecophysiological aspects of rapid population growth in a novel migratory blackcap (Sylvia atricapilla) population: an experimental approach. Oecologia. 1990;85(2):266-70.

18. Helbig AJ. Inheritance of migratory direction in a bird species: a crossbreeding experiment with SE- and SW-migrating blackcaps (Sylvia atricapilla). Behav Ecol Sociobiol. 1991;28(1):9-12.

19. Somveille M, Manica A, Butchart SHM, Rodrigues ASL. Mapping global diversity patterns for migratory birds. PLoS One. 2013;8(8):e70907.

20. Ehlers J, Gibbard PL. The extent and chronology of Cenozoic global glaciation. Quat Int. 2007:164-165:6-20

21. Greenberg R, Kozlenko A, Etterson M, Dietsch T. Patterns of density, diversity, and the distribution of migratory strategies in the Russian boreal forest avifauna. J Biogeogr. 2008;35(11):2049-60.

22. Somveille M, Rodrigues ASL, Manica A. Why do birds migrate? A macroecological perspective. Glob Ecol Biogeogr. 2015;24(6):664-74

23. Somveille M. The global ecology of bird migration: patterns and processes. Front Biogeography. 2016;8(3):e32694

24. McGuire JA, Witt CC, Remsen JV Jr, Dudley R, Altshuler DL. A higher-level taxonomy for hummingbirds. J Ornithol. 2009:150:155-65.

25. McGuire JA, Witt CC, Remsen JV Jr, Corl A, Rabosky DL, Altshuler DL, et al. Molecular phylogenetics and the diversification of hummingbirds. Curr Biol. 2014;24(8):910-6. 
26. Ornelas JF, González C, de los Monteros JA E, Rodríguez-Gómez F, GarcíaFeria LM. In and out of Mesoamerica: temporal divergence of Amazilia hummingbirds pre-dates the orthodox account of the completion of the Isthmus of Panama. J Biogeogr. 2014;41(1):168-81.

27. Pacheco MA, Battistuzzi FU, Lentino M, Aguilar RF, Kumar S, Escalante AA. Evolution of modern birds revealed by mitogenomics: timing the radiation and origin of major orders. Mol Biol Evol. 2011;28(6):1927-42.

28. del Hoyo J, Elliott A, Sargatal J. (eds.) Handbook of the Birds of the World, Vol. 5, Barn-owls to hummingbirds. Barcelona: Lynx Editions; 1999. p. 537680.

29. Clark CJ, Elias DO, Prum RO. Aeroelastic flutter produces hummingbird feather songs. Science. 2011;333(6048):1430-3.

30. Clark CJ, Feo JT, Van Dongen WFD. Sounds and courtship displays of the Peruvian Sheartail, Chilean Woodstar, oasis hummingbird, and a hybrid male Peruvian Sheartail x Chilean Woodstar. Condor. 2013;115(3):558-75.

31. Feo TJ, Musser MJ, Bery J, Clark CJ. Divergence in morphology, calls, song, mechanical sounds, and genetics supports species status for the Inaguan hummingbird (Trochilidae: Calliphlox" "evelynae" lyrura). Auk. 2014;132(1):248-64.

32. Licona-Vera Y, Ornelas JF. Genetic, ecological and morphological divergence between populations of the endangered Mexican Sheartail hummingbird (Doricha eliza). PLoS One. 2014;9(7):e101870.

33. Arizmendi MC, Berlanga H. Colibríes de México y Norteamérica. México, D.F: Comisión Nacional para el Conocimiento y Uso de la Biodiversidad (CONABIO); 2014.

34. Berthold P, Pulido F. Heritability of migratory activity in a natural bird population. Proc R Soc Lond B, Bot Sci. 1994;257(1350):311-5.

35. Pulido F, Berthold P, Mohr G, Querner U. Heritability of the timing of autumn migration in a natural bird population. Proc R Soc Lond B, Bot Sci. 2001;268(1470):953-9.

36. Pulido F, Berthold P. Current selection for lower migratory activity will drive the evolution of residency in a migratory bird population. Proc Natl Acad Sci USA. 2010;107(6):7341-6.

37. Malpica A, Ornelas JF. Postglacial northward expansion and genetic differentiation between migratory and sedentary populations of the broadtailed hummingbird (Selasphorus platycercus). Mol Ecol. 2014;23(2):435-52.

38. McKinney AM, CaraDonna PJ, Inouye DW, Barr B, Bertelsen CD, Waser NM. Asynchronous changes in phenology of migratory broad-tailed hummingbirds and their early- season nectar resources. Ecology. 2012;93(9):1987-93.

39. BirdLife International. Chaetocercus berlepschi. IUCN Red List of Threatened Species. Version 2013.2. International Union for Conservation of Nature. http://dx.doi.org/10.2305/IUCN.UK.2016-3.RLTS.T22688279A93190225.en. Retrieved 2 June 2017

40. IUCN. The IUCN Red List of Threatened Species. Version 3.1. Available: http://www.iucnredlist.org. Accessed 23 Nov 2013

41. McGuire JA, Witt CC, Altshuler DL, Remsen JV Jr. Phylogenetic systematics and biogeography of hummingbirds: Bayesian and maximum likelihood analyses of partitioned data and selection of an appropriate partitioning strategy. Syst Biol. 2007;56(5):837-56.

42. Müller K, Müller J, Neinhuis C, Quandt D. PhyDE - Phylogenetic Data Editor, v0.995. Available at: http://www.phyde.de. 2006.

43. Licona-Vera Y, Ornelas JF. Data from: the conquering of North America: dated phylogenetic and biogeographic inference of migratory behavior in bee hummingbirds. 2017. Dryad Digital Repository. http://dx.doi.org/10. 5061/dryad.68fno

44. Ronquist F, Huelsenbeck J. MrBayes 3: Bayesian phylogenetic inference under mixed models. Bioinformatics. 2003;19(12):1572-4.

45. Miller MA, Pfeiffer W, Schwartz T. Creating the CIPRES science Gateway for inference of large phylogenetic trees, Proceedings of the Gateway computing environments workshop (GCE), 14 Nov. 2010, New Orleans, LA. Washington, DC: Institute of Electrical and Electronics Engineers (IEEE); 2010. p. 1-8.

46. Darriba D, Taboada GL, Doallo R, Posada D. JModelTest 2: more models, new heuristics and parallel computing. Nat Methods. 2012;9:772.

47. Nylander JAA, Ronquist F, Huelsenbeck JP, Nieves-Aldrey JL. Bayesian phylogenetic analysis of combined data. Syst Biol. 2004;53(1):47-67.

48. Stamatakis A. RAxML Version 8: a tool for phylogenetic analysis and postanalysis or large phylogenies. Bioinformatics. 2014;30(9):1312-3.

49. Goloboff PA. NoName (NONA), Version 2.0. Program and documentation. Tucumán: Fundación Instituto Miguel Lillo; 1997.

50. Nixon KC. WinClada, Version 1.00.08. Program and Documentation. Ithaca (NY): Cornell University Press; 2002.
51. Drummond AJ, Suchard MA, Xie D, Rambaut A. Bayesian phylogenetics with BEAUti and the BEAST 1.7. Mol Biol Evol. 2012;8(29):1969-73.

52. Bouckaert R, Heled J, Kühnert D, Vaughan T, Wu C-H, Xie D, et al. BEAST 2: a software platform for Bayesian evolutionary analysis. PLoS Comput Biol. 2014;10(4):e1003537.

53. Drummond AJ, Ho SY, Phillips MJ, Rambaut A. Relaxed phylogenetics and dating with confidence. PLoS Biol. 2006;4(5):e88.

54. Lerner HRL, Meyer M, James HF, Hofreiter M, Fleischer RC. Multilocus resolution of phylogeny and timescale in the extant adaptive radiation of Hawaiian honeycreepers. Curr Biol. 2011;21(21):1838-44.

55. Yu Y, Harris AJ, He XJ. RASP (reconstruct ancestral state in phylogenies): a tool for historical biogeography. Mol Phylogenet Evol. 2015;87:46-9.

56. Nylander JAA, Olsson U, Alström P, Sanmartín I. Accounting for phylogenetic uncertainty in biogeography: a Bayesian approach to dispersal-vicariance analysis of the thrushes (Aves: Turdus). Syst Biol. 2008; 57(2):257-68.

57. Harris AJ, Xiang QY. Estimating ancestral distributions of lineages with uncertain sister groups: a statistical approach to dispersal-Vicariance analysis and a case using Aesculus L. (Sapindaceae) including fossils. J Syst Evol. 2009;47(5):349-68.

58. Blair C, Sánchez-Ramírez S. Diversity-dependent cladogenesis throughout western Mexico: evolutionary biogeography of rattlesnakes (Viperidae: Crotalinae: Crotalus and Sistrurus). Mol Phylogenet Evol. 2016:97:145-54.

59. Boyle WA. Altitudinal bird migration in North America. Auk. 2017;134(2):443-65

60. Winger BM, Lovette IJ, Winker DW. Ancestry and evolution of seasonal migration in the Parulidae. Proc R Soc B. 2012;279(1728):610-8.

61. Maddison WP, Maddison DR. Mesquite: a modular system for evolutionary analysis. Version 3.11. 2009-2016 [http://mesquiteproject.wikispaces.com].

62. Cunningham CW, Omland KE, Oakley TH. Reconstructing ancestral character states: a critical reappraisal. Trends Ecol Evol. 1998;13(9):361-6.

63. Cunningham CW. Some limitations of ancestral character-state reconstruction when testing evolutionary hypotheses. Syst Biol. 1999;48(3):665-74.

64. Ronquist F. Bayesian inference of character evolution. Trends Ecol Evo. 2004;19(9):475-81.

65. Ekman S, Andersen HL, Wedin M. The limitations of ancestral state reconstruction and the evolution of the ascus in the Lecanorales (lichenised Ascomycota). Syst Biol. 2008;57(1):141-56.

66. Schäffer S, Koblmüller S, Pfingstl T, Sturmbauer C, Krisper G. Ancestral state reconstruction reveals multiple independent evolution of diagnostic morphological characters in the "higher Oribatida" (Acari), conflicting with current classification schemes. BMC Evol Biol. 2010;10:246.

67. Yang Z, Kumar S, Nei M. A new method of inference of ancestral nucleotide and amino acid sequences. Genetics. 1995;141(4):1641-50.

68. Revell LJ. Two new graphical methods for mapping trait evolution on phylogenies. Methods Ecol Evol. 2013;4(8):754-9.

69. R Development Core Team. R: A language and environment for statistical computing. $\mathrm{R}$ foundation for statistical computing, Vienna, Available at: http://www.r-project.org/). 2012.

70. Felsenstein J. Phylogenies and the comparative method. Am Nat. 1985; 125(1):1-15.

71. Pagel M. The maximum likelihood approach to reconstructing ancestral character states of discrete characters on phylogenies. Syst Biol. 1999;48(3):612-22

72. Abrahamczyk S, Renner SS. The temporal build-up of hummingbird/plant mutualisms in North America and temperate South America. BMC Evol Biol. 2015;15:104.

73. Wiens JJ. Missing data and the design of phylogenetic analyses. J Biomed Inform. 2006;39(1):34-42.

74. Wiens JJ, Moen DS. Missing data and the accuracy of Bayesian phylogenetics. J Syst Evol. 2008;46(3):307-14.

75. Cerling TE, Harris JM, MacFadden BJ, Leakey MG, Quade J, Eisenmann V, et al. Global vegetation change through the Miocene/Pliocene boundary. Nature. 1997;389:153-8.

76. Zachos JC, Shackleton NJ, Revenaugh JS, Pälike H, Flower BP. Climate response to orbital forcing across the Oligocene-Miocene boundary. Science. 2001;292(5515):274-8.

77. Riddle B, Hafner D. A step-wise approach to integrating phylogeographic and phylogenetic biogeographic perspectives on the history of a core north American warm deserts biota. J Arid Environ. 2006;66(3):435-61. 
78. Good-Avila SV, Souza V, Gaut BS, Eguiarte LE. Timing and rate of speciation in Agave (Agavaceae). Proc Natl Acad Sci USA. 2006;103(24):9124-9.

79. Arakaki M, Christin P-C, Nyffeler R, Lendel A, Eggli U, Ogburn RM, et al. Contemporaneous and recent radiations of the world's major succulent plant lineages. Proc Natl Acad Sci USA. 2011;108(20):8379-84.

80. Hernández-Hernández T, Brown JW, Schlumpberger BO, Equiarte LE, Magallón S. Beyond aridification: multiple explanations for the elevated diversification of cacti in the new Wold succulent biome. New Phytol. 2014;202(4):1382-97.

81. Smith SA, Donoghue MJ. Combining historical biogeography with niche modelling in the Caprifolium clade of Lonicera (Caprifoliaceae, Dipsacales). Syst Bot. 2010;59(3):322-41.

82. Ornelas JF, Gándara E, Vásquez-Aguilar AA, Ramírez-Barahona S, Ortiz-Rodriguez AE, González C, et al. A mistletoe tale: postglacial invasion of Psittacanthus schiedeanus (Loranthaceae) to Mesoamerican cloud forests revealed by molecular and species distribution modeling. BMC Evol Biol. 2016;16:78.

83. Pérez-Crespo MJ, Ornelas JF, González-Rodríguez A, Ruiz-Sanchez E, Vásquez-Aguilar AA, Ramírez-Barahona S. Phylogeography and population differentiation in the Psittacanthus calyculatus (Loranthaceae) mistletoe: a complex scenario of the climate-volcanism interaction along the transMexican Volcanic Belt. J Biogeogr. 2017;00(0):00.

84. Wolfe AD, Randle CP, Datwyler SL, Morawetz JJ, Arguedas N, Díaz J. Phylogeny, taxonomic affinities, and biogeography of Penstemon (Plantaginaceae) based on ITS and cpDNA sequence data. Am J Bot. 2006;93(11):1699-713.

85. Azpeitia F, Lara C. Reproductive biology and pollination of the parasitic plant Psittacanthus calyculatus (Loranthaceae) in central Mexico. J Torrey Bot Soc. 2006;133(3):429-38.

86. Díaz Infante S, Lara C, Arizmendi MC, Eguiarte LE, Ornelas JF. Reproductive ecology and isolation of Psittacanthus calyculatus and $P$. auriculatus mistletoes (Loranthaceae). PeerJ. 2016;4:e2491.

87. Pérez-Crespo MJ, Lara C, Ornelas JF. Uncorrelated mistletoe infection patterns and mating success with local host specialization in Psittacanthus calyculatus (Loranthaceae). Evol Ecol. 2016;30(6):1061-80.

88. Abrahamczyk S, Souto-Vilarós D, McGuire JA, Renner SS. Diversity and clade ages of West Indian hummingbirds and the largest plant clades dependent on them: a 5-9 Myr young mutualistic system. Biol J Linn Soc. 2015;114(4):848-59.

89. Outlaw DC, Voelker G, Mila B, Girman DJ. The evolution of migration in, and historical biogeography of the Catharus thrushes: a molecular phylogenetic approach. Auk. 2003;120(2):299-310.

90. Milá B, Smith TB, Wayne RK. Postglacial population expansion drives the evolution of long-distance migration in a songbird. Evolution. 2006;60(11):2403-9.

91. Klicka J, Voelker G, Spellman GM. A molecular phylogenetic analysis of the "true thrushes" (Aves: Turdinae). Mol Phylogenet Evol. 2005;34(3):486-500.

92. Outlaw DC, Voelker G. Phylogenetic tests of hypotheses for the evolution of avian migration: a case study using the Motacillidae. Auk. 2006;123(2):455-66.

93. Ruegg KC, Hijmans RJ, Moritz C. Climate change and the origin of migratory pathways in the Swainson's Thrushcatharus ustulatus. J Biogeogr. 2006;33(7):1172-82.

94. Winker K, Pruett CL. Seasonal migration, speciation, and morphological convergence in the genus Catharus (Turdidae). Auk. 2006;123(4):1052-68.

95. Voelker G, Light JE. Palaeoclimatic events, dispersal and migratory losses along the afro-European axis as drivers of biogeographic distribution in Sylvia warblers. BMC Evol Biol. 2011;11:163.

96. Topp CM, Pruett CL, McCracken KG, Winker K. How migratory thrushes conquered northern North America: a comparative phylogeographic approach. PeerJ. 2013;1:e206.

97. Lovette IJ, Pérez-Emán JL, Sullivan JP, Banks RC, Fiorentino I, CórdobaCórdoba S, et al. A comprehensive multilocus phylogeny for the woodwarblers and a revised classification of the Parulidae (Aves). Mol Phylogenet Evol. 2010;57(2):753-70

98. Simpson RK, Johnson MA, Murphy TG. Migration and the evolution of sexual dichromatism: evolutionary loss of female coloration with migration among wood-warblers. Proc R Soc Lond B, Bot Sci. 2015;282(1809):20150375.

99. Joseph L, Lessa E, Christidis L. Phylogeny and biogeography in the evolution of migration: shorebirds of the Charadrius Complex. J Biogeogr. 1999;26(2):329-42.

100. Chesser R. Evolution in the high Andes: the phylogenetics of Muscisaxicola ground-tyrants. Mol Phylogenet Evol. 2000;15(3):369-80.

101. Winger BM, Barker FK, Ree RH. Temperate origins of long-distance seasonal migration in new world songbirds. Pro Natl Acad Sci USA. 2014;111(33):12115-20.
102. Cicero C, Johnson N. Molecular phylogeny and ecological diversification in a clade of new world songbirds (genus Vireo). Mol Ecol. 1998;7(10):1359-70.

103. Kondo B, Omland K. Ancestral state reconstructions of migration: multistate analysis reveals rapid changes in new world orioles (Icterus spp.). Auk. 2007;124(2):410-9

104. Rheindt F, Christidis L, Norman J. Habitat shifts in the evolutionary history of a Neotropical flycatcher lineage from forest and open landscapes. BMC Evol Biol. 2008;8:193.

105. Claramunt S, Derryberry EP, Remsen JV Jr, Brumfield RT. High dispersal ability inhibits speciation in a continental radiation of passerine birds. Proc R Soc Lond B, Bot Sci. 2012;279(1733):1567-74.

106. Johnson NY, Cicero C. New mitochondrial DNA data affirm the importance of Pleistocene speciation in north American birds. Evolution. 2004;58(5):1122-30.

107. Weir J, Schluter D. Ice sheets promote speciation in boreal birds. Proc R Soc Lond B, Bot Sci. 2004;271(1551):1881-7.

108. Lovette IJ. Glacial cycles and the tempo of avian speciation. Trends Ecol Evol. 2005;20(2):57-9.

109. Ruegg KC, Smith TB. Not as the crow flies: a historical explanation for circuitous migration in Swainson's thrush (Catharus ustulatus). Proc R Soc Lond B, Bot Sci. 2002;269(1498):1375-81.

110. Chamberlain CP, Bensch S, Feng X, Åkesson S, Andersson T. Stable isotopes examined across a migratory divide in Scandinavian willow warblers (Phylloscopus trochilus trochilus and Phylloscopus trochilus acredula) reflect their African winter quarters. Proc R Soc Lond B, Bot Sci. 2000;267(1438):43-8.

111. Bensch S, Grahn M, Muller N, Gay L, Åkesson S. Genetic, morphological, and feather isotope variation of migratory willow warblers show gradual divergence in a ring. Mol Ecol. 2009;18(14):3087-96.

112. Rolshausen G, Segelbacher G, Hobson KA, Schaefer M. Contemporary evolution of reproductive isolation and phenotypic divergence in sympatry along a migratory divide. Curr Biol. 2009;19(24):2097-101.

113. Procházka P, Stokke BG, Jensen H, Fainová D, Bellinvia E, Fossøy F, et al. Low genetic differentiation among reed warbler Acrocephalus scirpaceus populations across Europe. J Avian Biol. 2011;42(2):103-13.

114. Bairlein F, Norris DR, Nagel R, Bulte M, Voigt CC, Fox JW, et al. Crosshemisphere migration of a $25 \mathrm{~g}$ songird. Biol Lett. 2012;8(4):505-7.

115. Delmore KE, Hübner S, Kane NC, Schuster R, Andrew RL, Câmara F, et al. Genomic analysis of a migratory divide reveals candidate genes for migration and implicates selective sweeps in generating islands of differentiation. Mol Ecol. 2015;24(8):1873-88.

116. Delmore KE, Toews DPL, Germain RR, Owens GL, Irwin DE. The genetics of seasonal migration and plumage color. Curr Biol. 2016;26(16):2167-73.

\section{Submit your next manuscript to BioMed Central and we will help you at every step:}

- We accept pre-submission inquiries

- Our selector tool helps you to find the most relevant journal

- We provide round the clock customer support

- Convenient online submission

- Thorough peer review

- Inclusion in PubMed and all major indexing services

- Maximum visibility for your research

Submit your manuscript at www.biomedcentral.com/submit
Biomed Central 